\title{
Should we recommend e-cigarettes to help smokers quit?
}

Smokers want to vape, it can help them quit, and it's less harmful than smoking, say Paul Aveyard and Deborah Arnott. But Kenneth $\mathbf{C}$ Johnson argues that smokers who vape are generally less likely to quit and is concerned about youth vaping as a gateway to smoking, dual use, and potential harms from long term use

\section{Paul Aveyard professor of behavioural medicine ${ }^{1}$, Deborah Arnott chief executive ${ }^{2}$, Kenneth C Johnson adjunct professor ${ }^{3}$}

${ }^{1}$ Nuffield Department of Primary Care Health Sciences, University of Oxford, Oxford, UK; ${ }^{2}$ Action on Smoking and Health, London, UK; ${ }^{3}$ School of Epidemiology and Public Health, University of Ottawa, Ottawa, Ontario, Canada

\section{Yes-Paul Aveyard, Deborah Arnott}

Smokers are asking their doctors for advice on using electronic cigarettes, and guidance is clear on what doctors in England and Wales should say. The National Institute for Health and Care Excellence (NICE) says that smokers should be told that many people have found e-cigarettes helpful aids to cessation, and the evidence indicates that e-cigarettes are substantially less harmful to health than smoking, although not risk free. ${ }^{1}$

E-cigarettes seem to double the likelihood of achieving abstinence and seem as effective as nicotine replacement therapy (NRT) in supporting cessation, according to the few trials and appropriately conducted cohort studies. ${ }^{23}$ This conclusion is bolstered by evidence that NRT and e-cigarettes have a similar pharmacological profile. ${ }^{4}$

\section{Smokers want e-cigarettes}

What makes e-cigarettes remarkable is that so many smokers who wish to cut down or stop choose e-cigarettes over NRT, ${ }^{5}$ even though NRT is cheaper because it is available on prescription. E-cigarettes are popular cessation aids, and this may have led to increases in the success of quit attempts in the population and quitting as a whole in England and the United States. $^{67}$

NRT is most effective when it is prescribed and combined with behavioural support. ${ }^{8}$ Observational evidence indicates the same may be true for e-cigarettes. ${ }^{9}$ Licensing e-cigarettes as another form of NRT could be of financial benefit. NICE has estimated that for every pound invested in cessation, $£ 2.37$ could be saved on treating smoking related diseases and the cost of reduced productivity. ${ }^{10}$

Some experts fear that transferring addiction from tobacco to e-cigarettes leads to continued vaping, which may be harmful.
In England, where vaping has been popular for at least six years, most people who vape but do not smoke have stopped smoking recently. ${ }^{5}$ One cohort study showed that most people who stopped smoking after a period of dual use also stopped vaping within six months. ${ }^{11}$

For most vapers, the uncertainty around harms may be largely irrelevant provided that vaping is short term. Although there are no studies of the harms from long term vaping, the consensus is that any direct harm is likely to be a fraction of that from smoking. ${ }^{42}$ Continued vaping is preferable to continued smoking.

Worries about long term dual use of e-cigarettes and combustible tobacco are insufficiently evidenced. And in the short term, dual use may aid cessation. ${ }^{13-15}$

\section{Young people}

The age of sale for e-cigarettes in the UK is 18 and advertising is limited, with no television, radio, internet, or print advertising allowed. Experimentation with e-cigarettes is relatively common among young people, but regular use by young people who have never smoked is rare, with between 1 in 200 and 1 in 500 vaping at least once a week. ${ }^{16}$ Weekly use seems necessary to trigger persistent desire for nicotine.

At a time when experimental vaping has become more common, the prevalence of youth smoking has fallen to unprecedented lows. ${ }^{17}$ With few people using the gate, it seems the gateway effect is at worst a small problem. And clear advice from doctors that these products should be used only for cessation could help keep it low. 


\section{E-cigarettes don't help big tobacco}

Concerns have been raised about the tobacco industry's involvement in the e-cigarette market, and that endorsement of vaping risks supporting companies that profit from tobacco. However, the evidence suggests that e-cigarettes are not benefiting the tobacco industry because smoking prevalence is falling. $^{7}$

What is essential is that, as in the UK, e-cigarettes are part of a comprehensive anti-smoking strategy that protects public policy from the commercial interests of the tobacco industry and regulates with that in mind.

Although some countries, including the US and Australia, have adopted cautious stances on e-cigarettes, many of their residents disagree, and there are concerted campaigns for e-cigarettes to be recommended for smoking cessation. Other countries such as France and New Zealand have a similar stance to the UK.

UK health policy promotes vaping as an alternative to smoking. This has consensus among our public health community, with the endorsement of Cancer Research UK and other charities, medical royal colleges, and the BMA. ${ }^{18-22}$ Why? Because in Britain it's clear that at the same time as e-cigarettes became the most popular quitting aid, smoking rates fell faster than before and are now at the lowest ever recorded levels for both adults and children.

\section{No-Kenneth C Johnson}

Research is replacing optimistic speculation about e-cigarettes, with sobering evidence emerging of the limits and hazards of their use as a cessation aid.

The overall evidence is that e-cigarettes as actually used depress, not assist, cigarette smoking cessation. ${ }^{23}$ The 2018 Public Health England report concludes "there is insufficient evidence from randomized controlled trials about the effectiveness of e-cigarettes as cessation aids compared with no treatment." ${ }^{24}$ The one controlled trial of e-cigarettes versus nicotine replacement therapy for quitting smoking has found no significant difference in verified quit rates at six months between nicotine e-cigarettes (7.3\%) and patches $(5.8 \%)$. ${ }^{23}$ And that study compared giving people e-cigarettes with giving them a coupon that could be redeemed for NRT, hardly a fair comparison. So what is to be gained by using e-cigarettes over NRT on prescription?

While there is some evidence that smokers who are daily users of high dose e-cigarettes (10\%-20\% of vapers) do quit more, the other $80 \%-90 \%$ fare worse, with vapers significantly less likely than non-users to quit. ${ }^{25}$ A meta-analysis of 25 "real world" studies found that smokers using e-cigarettes were $27 \%$ less likely to stop smoking than non-vapers. ${ }^{23} \mathrm{~A}$ recent European Union study, which included specific analysis of Great Britain also found that vapers were less likely to stop smoking than non-vapers. ${ }^{26}$

\section{Addicting a new generation}

Although advocates of e-cigarettes argue otherwise, ${ }^{24}$ evidence strongly and consistently indicates a gateway for addicting new generations of young smokers. ${ }^{27}$ The 2018 US National Academy of Sciences, Engineering, and Medicine report found "substantial evidence that e-cigarette use increases risk of ever using combustible tobacco cigarettes among youth and young adults." ${ }^{12}$ A meta-analysis of nine published longitudinal studies of youth suggest a gateway effect, with e-cigarette use at baseline among non-smokers associated with four times the chance of being a smoker at follow-up compared with youth who had never tried e-cigarettes, even after adjusting for psychological and behavioural risk factors associated with smoking cigarettes. ${ }^{23}$ And in a well designed 2016 longitudinal study among 1152 English 11-18 year olds, the never smokers who had ever tried e-cigarettes at baseline were 12 times more likely than never users to have become smokers at follow-up (a worrying 52\% became smokers). ${ }^{28}$

E-cigarettes are expanding the nicotine market, recruiting youth unlikely to start nicotine use with cigarettes. About a quarter of youth who have tried vaping do not fit the risk taking profile of the youth smoker, and yet many of this subset of e-cigarette users become established cigarette smokers. ${ }^{23}$

A study quantifying US population level health benefits and harms of e-cigarettes in 2015 estimated about eight new young smokers for every adult smoker who quit, yielding a substantial net negative effect on public health. ${ }^{29}$

Widespread dual use of cigarettes and e-cigarettes undermines harm reduction. In 2014, $93 \%$ of e-cigarette users in the US also reported smoking cigarettes, $83 \%$ in France, and 60\% in England. ${ }^{23}$

\section{Risk of heart disease}

Smokers who do shift completely to e-cigarettes reduce exposure to 70 known carcinogens in tobacco smoke and would be expected to reduce their cancer risk. ${ }^{23}$ However, two thirds of deaths associated with smoking are from heart disease (48\%) and non-cancer lung conditions (17\%). ${ }^{2330}$ Like cigarettes, e-cigarettes deliver ultrafine particles and nicotine deep into the lungs where they are absorbed into the bloodstream. They damage the heart, blood vessels, and lungs, even at low doses. Just one cigarette a day results in half the heart disease risk and $30 \%$ of the stroke risk of smoking 20 cigarettes a day. ${ }^{31}$

Direct evidence of a link between e-cigarette use and heart disease emerged earlier this year. In a cross sectional study of 70000 people, daily conventional cigarette smoking resulted in a risk factor adjusted $172 \%$ increase in risk of heart attack. Daily e-cigarette use was independently associated with a $79 \%$ increase in heart attack risk (95\% confidence interval $20 \%$ to $166 \%$ ) after conventional cigarette use and demographic and health characteristics were taken into account. ${ }^{32}$

Tobacco companies are expanding the e-cigarette market ${ }^{23}$ and using all too familiar tobacco marketing strategies. ${ }^{33}$ They have a long history of aggressively using their economic and political power to profit at the expense of public health. British American Tobacco has plans for expanding the recreational nicotine market with e-cigarettes - and cessation is not part of the game plan. ${ }^{34}$ The cruel legacy of a century of epidemic nicotine addiction and smoking related death and disability is a cautionary tale. The net effect of e-cigarettes on smoking cessation is negative, high levels of dual use undermine harm reduction, and gateway risks for youth smoking initiation are a demonstrated danger. Recommending e-cigarettes for smoking cessation, as currently promoted and used, is irresponsible.

Competing interests: All authors have read and understood BMJ policy on declaration of interests and declare the following interests: PA conducts independent research on smoking cessation and harm reduction funded by public bodies. $\mathrm{He}$ was chief investigator of a smoking cessation trial funded by the National Institute of Health for which GlaxoSmithKline donated nicotine patches to the NHS in support of excess treatment costs. DA is chief executive of Action on Smoking and Health, which receives funding from the British Heart Foundation and Cancer Research UK. She was a member of the NICE committee that developed the 2018 guidance on smoking cessation interventions and services. 
Provenance and peer review: Commissioned; externally peer reviewed.

1 National Institute for Health and Clinical Excellence. Stop smoking interventions and services NICE guideline NG92 2018. https://www.nice.org.uk/guidance/ng92

2 Hartmann-Boyce J, McRobbie H, Bullen C, Begh R, Stead LF, Hajek P. Electronic cigarettes for smoking cessation. Cochrane Database Syst Rev 2016;9:CD010216. 10.1002/14651858.CD010216.pub3. 27622384

3 Hartmann-Boyce J, Begh R, Aveyard P. Electronic cigarettes for smoking cessation. BMJ 2018;360:j5543. 10.1136/bmj.j5543 29343486

4 McNeill A, Brose LS, Calder R, etal. Evidence review of ecigarettes and heated tobacco products 2018. A report commissioned by Public Health England. Public Health England, 2018.

5 West R, Beard E, Brown J. Trends in electronic cigarette use in England: Smoking Toolkit Study. 2018. http://www.smokinginengland.info/latest-statistics/

6 Beard E, West R, Michie S, Brown J. Association between electronic cigarette use and changes in quit attempts, success of quit attempts, use of smoking cessation pharmacotherapy, and use of stop smoking services in England: time series analysis of population trends. BMJ 2016;354:i4645. 10.1136/bmj.i4645 27624188

7 Zhu S-H, Zhuang Y-L, Wong S, Cummins SE, Tedeschi GJ. E-cigarette use and associated changes in population smoking cessation: evidence from US current population surveys. BMJ 2017;358:j3262. 10.1136/bmj.j3262 28747333

8 Stead LF, Koilpillai P, Fanshawe TR, Lancaster T. Combined pharmacotherapy and behavioural interventions for smoking cessation. Cochrane Database Syst Rev 2016;3:CD008286. 10.1002/14651858.CD008286.pub3. 27009521

9 NHS Digital. Statistics on NHS stop smoking services. 2017 https://digital.nhs.uk/catalogue/ PUB30058.

10 Pokhrel S, Owen L, Coyle K, etal . Costs of disinvesting from stop smoking services: an economic evaluation based on the NICE Tobacco Return on Investment model. Lancet 2016;388:S95. 10.1016/S0140-6736(16)32331-5 27968915

11 Pasquereau A, Guignard R, Andler R, Nguyen-Thanh V. Electronic cigarettes, quit attempts and smoking cessation: a 6-month follow-up. Addiction 2017;112:1620-8. 10.1111/add.13869 28504457

12 National Academies of Sciences, Engineering, and Medicine. Public health consequences of e-cigarettes. National Academies Press, 2018.

13 Moore D, Aveyard P, Connock M, Wang D, Fry-Smith A, Barton P. Effectiveness and safety of nicotine replacement therapy assisted reduction to stop smoking: systematic review and meta-analysis. BMJ 2009;338:b1024. 10.1136/bmj.b1024 19342408

14 Beard E, McNeill A, Aveyard P, Fidler J, Michie S, West R. Association between use of nicotine replacement therapy for harm reduction and smoking cessation: a prospective study of English smokers. Tob Control 2013;22:118-22. 10.1136/tobaccocontrol-2011-050007 22135165

15 Hartmann-Boyce J, Begh R, Aveyard P. Electronic cigarettes for smoking cessation. BMJ 2018;360:j5543. 10.1136/bmj.j5543 29343486

16 Bauld L, MacKintosh AM, Eastwood B, etal . Young people's use of e-cigarettes across the United Kingdom: findings from five surveys 2015-2017. Int J Environ Res Public Health 2017; 14:E973. 10.3390/ijerph14090973 28850065

17 NHS Digital. Smoking, drinking and drug use among young people. 2017. https://digital. nhs.uk/catalogue/PUB30132.
18 Department of Health. Towards a smokefree generation. A tobacco control plan for England. Department of Health, 2017.

19 Cancer Research UK. E-cigarettes. CRUK, 2018.

20 Royal College of General Practitioners. RCGP position statement on the use of electronic nicotine vapour products. RCGP, 2017.

21 Tobacco Advisory Group of Royal College of Physicians. Nicotine without smoke: tobacco harm reduction. $\mathrm{RCP}, 2016$.

22 British Medical Association. E-cigarettes: balancing risks and opportunities. BMA, 2017.

23 Glantz SA, Bareham DW. E-Cigarettes: use, effects on smoking, risks, and policy implications. Annu Rev Public Health 2018;39:215-35. 10.1146/annurev-publhealth-040617-013757 29323609

24 McNeill A, Brose LS, Calder R, Bauld L, Robson D. Evidence review of e-cigarettes and heated tobacco products 2018. A report commissioned by Public Health England. Public Health England, 2018.

25 Hitchman SC, Brose LS, Brown J, Robson D, McNeill A. Associations between e-cigarette type, frequency of use, and quitting smoking: findings from a longitudinal online panel survey in Great Britain. Nicotine Tob Res 2015;17:1187-94. 10.1093/ntr/ntv078 25896067

26 Kulik MC, Lisha NE, Glantz SA. E-cigarettes associated with depressed smoking cessation: a cross-sectional study of 28 European Union countries. Am J Prev Med 2018:54:603-9. 10.1016/j.amepre.2017.12.01729449132

27 Chapman S, Bareham D, Maziak W. The gateway effect of e-cigarettes; reflections on main criticisms. Nicotine Tob Res 2018. [Epub ahead of print.] 10.1093/ntr/nty067. 29660054

28 East K, Hitchman S, Bakolis I, Williams S, Cheeseman H, Arnott D, McNeill A. Association between smoking and electronic cigarette use in a cohort of young people. J Adolesc Health 2018 Feb 21. pii: S1054-139X(17)30903-5. [Epub ahead of print.] 10.1016/j.jadohealth.2017.11.301

29 Soneji SS, Sung H-Y, Primack BA, Pierce JP, Sargent JD. Quantifying population-leve health benefits and harms of e-cigarette use in the United States. PLoS One 2018;13:e0193328. 10.1371/journal.pone.0193328 29538396

30 World Health Organization. WHO global report: mortality attributable to tobacco. WHO, 2012.

31 Hackshaw A, Morris JK, Boniface S, Tang JL, Milenković D. Low cigarette consumption and risk of coronary heart disease and stroke: meta-analysis of 141 cohort studies in 55 study reports. BMJ 2018;360:j5855. 10.1136/bmj.j5855 29367388

32 Alzahrani T, Pena I, Temesgen N, Stanton Glantz SA. Association between electronic cigarette use and myocardial infarction: results from the 2014 and 2016 national health interview surveys. Society for Research on Nicotine and Tobacco, 24th annual meeting, Baltimore 21-24 Feb, 2018. Abstract POS5-34. https://c.ymcdn.com/sites/www.srnt.org/ resource/resmgr/conferences/2018_Annual_Meeting/65388_SRNT_2018_Rapids_Abstr. pdf\#page $=12$

33 de Andrade M, Hastings G, Angus K. Promotion of electronic cigarettes: tobacco marketing reinvented?BMJ 2013;347:f7473. 10.1136/bmj.f7473. 24361526

34 Callard C. OMG! BAT's plans for next generation products. Physicians for a Smoke-Free Canada, 2 Nov 2017. http://smoke-free-canada.blogspot.ca/2017/11/bats-plans-for-nextgeneration-products.html

Published by the BMJ Publishing Group Limited. For permission to use (where not already granted under a licence) please go to http://group.bmj.com/group/rights-licensing/ permissions 